University of Tennessee Health Science Center UTHSC Digital Commons

Summer 7-2018

\title{
Efficacy of Smart Infusion Pumps from a Nursing Perspective
}

Kassi B. Zaborowski

University of Tennessee Health Science Center

Follow this and additional works at: https://dc.uthsc.edu/hiimappliedresearch

Part of the Health and Medical Administration Commons, Health Information Technology Commons, Nursing Commons, and the Other Analytical, Diagnostic and Therapeutic Techniques and Equipment Commons

\section{Recommended Citation}

Zaborowski, Kassi B., "Efficacy of Smart Infusion Pumps from a Nursing Perspective" (2018). Applied Research Projects. 57. . https://doi.org/10.21007/chp.hiim.0057

https://dc.uthsc.edu/hiimappliedresearch/57

This Research Project is brought to you for free and open access by the Department of Health Informatics and Information Management at UTHSC Digital Commons. It has been accepted for inclusion in Applied Research Projects by an authorized administrator of UTHSC Digital Commons. For more information, please contact jwelch30@uthsc.edu. 
Running head: EFFICACY OF SMART INFUSION PUMPS

Efficacy of Smart Infusion Pumps from a Nursing Perspective

Kassi B. Zaborowski

The University of Tennessee Health Science Center

July 2018 


\title{
EFFICACY OF SMART INFUSION PUMPS
}

\begin{abstract}
In today's healthcare, intravenous (IV) therapy-related errors have become rampant and are responsible for a substantial portion of hospital injuries and deaths. In the last decade, however, since the development and implementation of "smart" IV pumps, a significant number of these IV medication errors have allegedly been reduced. The purpose of this paper is to discuss research surrounding an evaluation of the efficacy of smart IV pumps from a nursing perspective.
\end{abstract}




\section{EFFICACY OF SMART INFUSION PUMPS}

Table of Contents

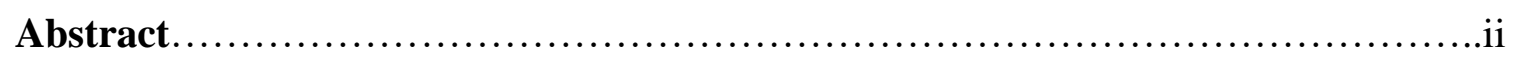

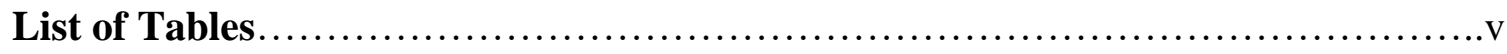

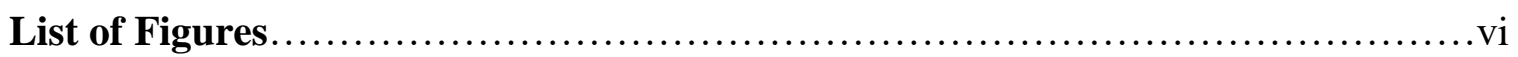

\section{Chapter 1: Introduction}

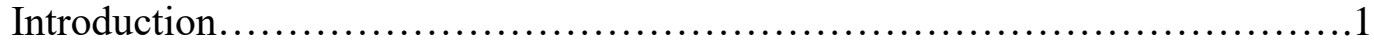

Background of the Problem.............................................

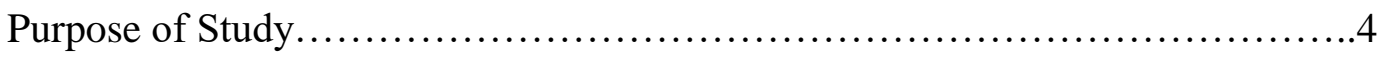

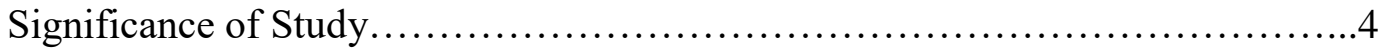

Research Questions...................................................5

Definition of Terms.................................................

Limitations................................................................. 8

\section{Chapter 2: Review of the Literature}

Method.............................................................8

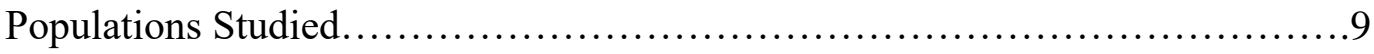

Survey Method...................................................... 9

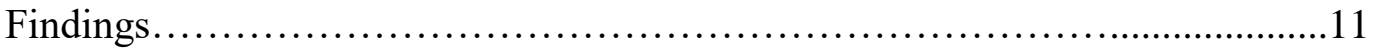

Limitations.................................................... 15

Conclusion............................................................. 16

\section{Chapter 3: Methodology}

Research Design.....................................................17

Population and Sample Design............................................ 17

Data Collection Procedure/Instrument..................................... 17

Response Rate.................................................... 18

Profile of Sample.................................................... 18

Research Questions................................................. 18

\section{Chapter 4: Results}

Response Rate of Sample............................................ 18 


\section{EFFICACY OF SMART INFUSION PUMPS}

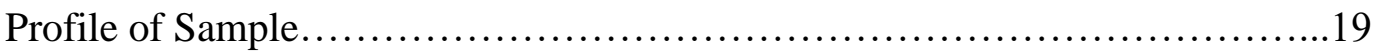

Research Questions................................................20

Chapter 5: Summary, Conclusions, and Recommendations

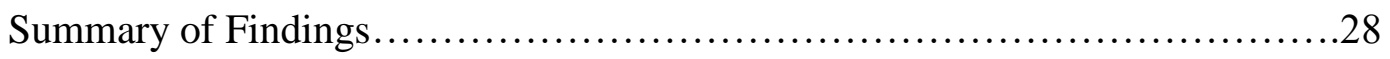

Conclusions and Recommendations.......................................30

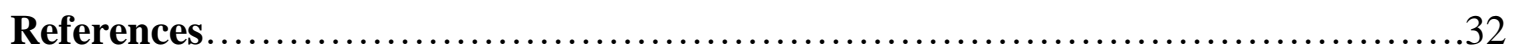




\section{EFFICACY OF SMART INFUSION PUMPS}

\section{List of Tables}

Table 3. Examples of Errors with Potential Harms..................................11 


\section{EFFICACY OF SMART INFUSION PUMPS}

\section{List of Figures}

Figure 2. Screen shot of the data collection tool (REDCap) ......................... 


\section{EFFICACY OF SMART INFUSION PUMPS}

\section{Efficacy of Smart Infusion Pumps from a Nursing Perspective}

\section{Chapter 1: Introduction}

\section{Introduction.}

According to the U.S. Food \& Drug Administration (2016), medication errors are responsible for at least one death every day and injure an astonishing 1.5 million people annually in the United States alone. Since IV medications, when compared with medications delivered via other routes, lead to higher systemic bodily concentrations and produce more rapid, potentially irreversible side effects, they are twice as likely to cause patient harm (Reston, 2013). Interestingly, Dulak (2005) estimates that, on average, 90\% of hospitalized patients receive IV therapy in some capacity. Even though a medication mishap can occur anywhere in the prescribing, packaging, dispensing, administering, or monitoring processes, studies have indicated a larger than normal error rate $(73 \%)$ in the actual administration process. The development of the smart IV pump, however, when used according to its design, has become a necessary component of a comprehensive and safe medication system, one that has successfully combatted error-related issues in this administration process. According to a recent survey, nearly $80 \%$ of hospitals in the United States currently utilize IV smart pump technology (Association for the Advancement of Medical Instrumentation [AAMI], 2016).

\section{Background of the Problem.}

The first programmable and very basic IV infusion pumps were developed more than 40 years ago (Proctor, 2014). Although these pumps were regarded as quite innovative at the time, they allowed the caregiver to input only limited information, such 


\section{EFFICACY OF SMART INFUSION PUMPS}

as the medication's volume-to-be-infused (VTBI) and the infusion rate. Lacking in technological sophistication, these pumps were risky in that they allowed for a wide range of medication programming with no alerts or alarms. For instance, all medications or blood products, even those considered high-alert or high-risk such as insulin, opiates, anti-coagulants, and sedatives could be infused at various rates starting as low as 0.1 milliliters (mL) per hour to as high as $999 \mathrm{~mL}$ or more per hour. Over the years, these shortcomings have led to patients receiving lethal doses of medications. According to the U.S. Food \& Drug Administration (2016), there were 56,000 reports of infusion-related incidents, including 710 deaths, resulting in the recall of 87 infusion pumps in the United States.

It wasn't until the late 1990 s that smart IV pumps became the catalyst for change. A technological breakthrough, electronically erasable programmable read-only memory (EEPROM), made it possible for infusion pumps to contain safety software that could be customized to a hospital's specific care area and tailored to meet individual patient needs (Proctor, 2014). Dose error-reduction systems (DERS) embedded within smart pumps have drastically improved the safety of IV infusion therapies. Unlike the former infusion pumps, predetermined drug libraries now produce an alert if pump programming exceeds hospital-established limits. Most smart pump software provides soft alerts, or soft stops, as well as hard alerts, or hard stops. Soft stops prompt users to reconsider a given drug dosage but have limitations in that they purely serve as a reminder and can be overridden; hard stops, however, abruptly prevent users from proceeding beyond the stated dose limits (Reston, 2013). Hard stops have proven to be more effective since they do not allow easy circumvention; smart pumps also log alerts including the time, date, drug, 


\section{EFFICACY OF SMART INFUSION PUMPS}

concentration, programmed rate, and volume to be infused, allowing for valuable continuous quality improvement (CQI) data (Dulak, 2005). Most smart pump programs continuously display the name of the medication being infused, the dose, the rate, and the volume left to be infused, as well.

It is evident that smart pumps now have the capability to prevent errors related to incorrect programming, but it is important to note that infusion-related errors can still occur if the wrong medication is given to the right patient, even if the pump is programmed correctly for the given medication. When a barcode medication administration system is integrated with a smart pump, however, the Five Rights of Medication Administration, which entails giving the right dose of the right medication to the right patient via the right route at the right time, becomes increasingly more accurate (Dulak, 2005). The numerous benefits of smart infusion technologies are clear, but it is important to understand that a smart pump's efficacy is dependent on its user. Poor caregiver compliance with the drug library and dosage limits can drastically limit the advantages of smart pump decision support. Due to poor implementation and communication processes, one study conducted at an independent community hospital in Massachusetts found that the nursing staff utilized the smart pump library with only $37 \%$ of all infusions (Harding, n.d.). Some nurses felt that pump programming was frequently rushed or omitted altogether due to time constraints and competing work demands. In 2005, another study that involved 735 cardiac surgery patients resulted in 14 adverse events. Perhaps these outcomes could have been prevented had the nursing staff not bypassed the drug library, an occurrence that happened $25 \%$ of the time (Reston, 2013). 


\section{EFFICACY OF SMART INFUSION PUMPS}

\section{Purpose of Study.}

Thus, the purpose of this study is to gauge the extent of which obstetrical nurses at five East Tennessee hospitals perceive smart IV infusion pumps as helpful in improving patient safety by reducing harm. This research also aims to evaluate the prevalence of the proper use of smart IV pumps by the nursing staff. This study also gathers participant demographic information to assess for trends.

\section{Significance of Study.}

Medication errors associated with IV pumps are historically proven to occur frequently, have the potential to cause harm, and are epidemiologically diverse (Husch, Sullivan, Rooney, Barnard, Fotis, Clarke, \& Noskin, 2005). Proctor (2014), however, emphasizes the following benefits since the widespread implementation of smart IV pumps: fostered development of drug dose limits, standardization of concentration and dosing units, allowance of hospitals to configure pumps to match applications, provision of a plethora of infusion data, documentation of "good catches" from prevented programming errors, promotion of wireless connectivity/server applications, and identification of human factors and opportunities for manufacturer improvements. Since smart IV pumps demonstrate these numerous potential benefits to the already risky medication administration process, it is important to assess and encourage the proper use by the nurses who directly interact with them. Moreover, patients deserve the safest medical care and with the evolution of technological advancements, such as said smart IV pumps, desirable clinical outcomes have become even easier to attain. 


\section{EFFICACY OF SMART INFUSION PUMPS}

\section{Research Questions.}

This anonymously-reported study contains three basic demographic questions followed by four smart IV pump-related statements in which the nurse is asked to rank his/her agreement, disagreement, or indifference accordingly. The last question provides an optional free-text comment box. The questions/statements and available responses are as follows:

1. How long have you practiced BEDSIDE nursing?
$0 \quad<1$ year
○ 1-3 years
○ 4-10 years
○ 11-20 years
○ >20 years

2. What shift do you primarily work?
○ Dayshift
○ Nightshift
○ PRN
- Varies/No Set Shift

3. What is your age?
○ 22-30 Years Old
- 31-40 Years Old
○ 41-50 Years Old
○ 51-60 Years Old
○ >60 Years Old 


\section{EFFICACY OF SMART INFUSION PUMPS}

4. Smart IV pumps improve patient safety by reducing harm associated with medication errors.
- Strongly Agree
○ Agree
- Indifferent/Unsure
○ Disagree
- Strongly Disagree

5. The presence of embedded alerts, alarms, and/or functionalities that deny overriding have prevented the following IV-related error(s) in my clinical past (select all that apply):
○ Blood/Blood Product(s)
- Medication(s)
$\circ \quad$ IV Fluid(s)
- None
○ Unsure

6. Learning to operate smart IV pumps is easy and user-friendly.
- Strongly Agree
- Agree
- Indifferent/Unsure
○ Disagree
- Strongly Disagree 


\section{EFFICACY OF SMART INFUSION PUMPS}

7. Smart IV pumps' eventual integration with the eMAR, CPOE, and barcode scanning systems will further improve patient safety (i.e. scanning the patient's armband + scanning the IV infusion(s) = automatic pump programming).

- Strongly Agree

- Agree

- Indifferent/Unsure

- Disagree

- Strongly Disagree

8. Comments?

\section{Definition of Terms.}

For clarification purposes, the following is a list of terms used within this research project and their meanings:

1. Anti-coagulants - a drug that acts to prevent blood clots by thinning the blood.

2. Barcode medication administration system - the use of an electronic device, specifically a barcode scanner, that can read/scan the barcode on a patient's hospital armband and on medication labels to aid in medication error prevention.

3. Cardiac - of, or relating to, the human heart.

4. Computerized provider order entry (CPOE) - an electronic means for a licensed healthcare provider to input patient care orders.

5. Electronic medication administration record (eMAR) - an electronic report that serves as a legal record of drugs administered to a patient. 


\section{EFFICACY OF SMART INFUSION PUMPS}

6. Infusion rate - the rate, usually measured as $\mathrm{mL} /$ minute or $\mathrm{mL} / \mathrm{hour}$, at which an IV-related therapy is administered to achieve therapeutic effectiveness.

7. Insulin - a hormone that can be administrated via the IV or subcutaneous (SQ) route to decrease blood glucose levels.

8. Intravenous - associated with, or administered into, a vein or veins.

9. Opiates - a drug with Morphine-like effects, derived from opium.

10. Sedatives - a drug that acts to induce sleep and/or promote calmness.

11. Volume-to-be-infused (VTBI) - the total amount, usually measured in $\mathrm{mL}$, that a patient is to receive of a provider-ordered IV therapy.

\section{Limitations.}

This study is limited in that it will only be conducted and representative of one nursing specialty within five hospitals in the United States. Additionally, due to its localized distribution within East Tennessee facilities only, the survey is not geographically demonstrative of the entire nation. Additionally, Since the questionnaire/survey will be distributed via e-mail, it is highly unlikely that there will be a $100 \%$ response rate, especially with email recipients who don't periodically check their email inbox or work often. This study is also limited in that it pertains to registered nurses practicing in an inpatient setting only, thus excluding ambulatory scenarios.

\section{Chapter 2: Review of Literature}

\section{Method.}

The purpose of this excerpt is to review the literature surrounding smart IV pumps to determine its efficacy, or lack thereof. Electronic articles for this literature review surrounding IV smart pumps were retrieved from the PubMed database. The search was 


\section{EFFICACY OF SMART INFUSION PUMPS}

confined to the human species with publication dates between the years of 2005 to the present. Articles in the English language only were of interest. The search was further limited to the following free full-text articles: clinical trials, journal articles, metaanalyses, reviews, and systematic reviews. The following search terms were employed: "IV smart pump" OR "IV smart pumps” OR “smart IV pump” OR “smart IV pumps" OR “smart pump" OR “smart pumps” OR "smart infusion technology” OR "smart infusion pump” OR “smart infusion pumps”. This very specific search yielded a total of 13 articles. Of those, only 3 articles, which I will further discuss in this paper, contained data and pertinent information for the purposes of this research.

\section{Populations Studied.}

The first study took place at Brigham and Women's Hospital (BWH), a 793-bed tertiary care academic medical center in Boston, Massachusetts. Data was collected from 55 inpatients from three different clinical areas: one medical intensive care unit (ICU), one surgical ICU, and one general surgical unit. The second study focused on a patient population from the ICU setting where 4,604 critically ill adults from one academic and

one non-academic medical center were under scrutiny. This study examined 20,000 beddays of care in surgical, trauma/burn, and medical ICUs (Nuckols et al., 2008). The third case was conducted at a 500-bed women and pediatrics specialty hospital.

\section{Survey Method.}

The literature revealed various methods for conducting research within each of the three studies. The first journal article used a prospective point prevalence approach. Designated observation nurses were responsible for comparing, at the bedside, the 


\section{EFFICACY OF SMART INFUSION PUMPS}

medication, dose, and rate on the smart pump against the prescriber's orders in the medical record. To confirm that an error was present, two observers had to be in agreement. An observational tool was developed to collect all IV medication error data. This particular tool was developed using the REDCap application, a Health Insurance Portability and Accountability Act (HIPAA)-compliant, web-based application that can be accessed via personal computers and/or cell phones (Nuckols et al., 2008). Figure 2 below provides a screenshot of the REDCap tool:

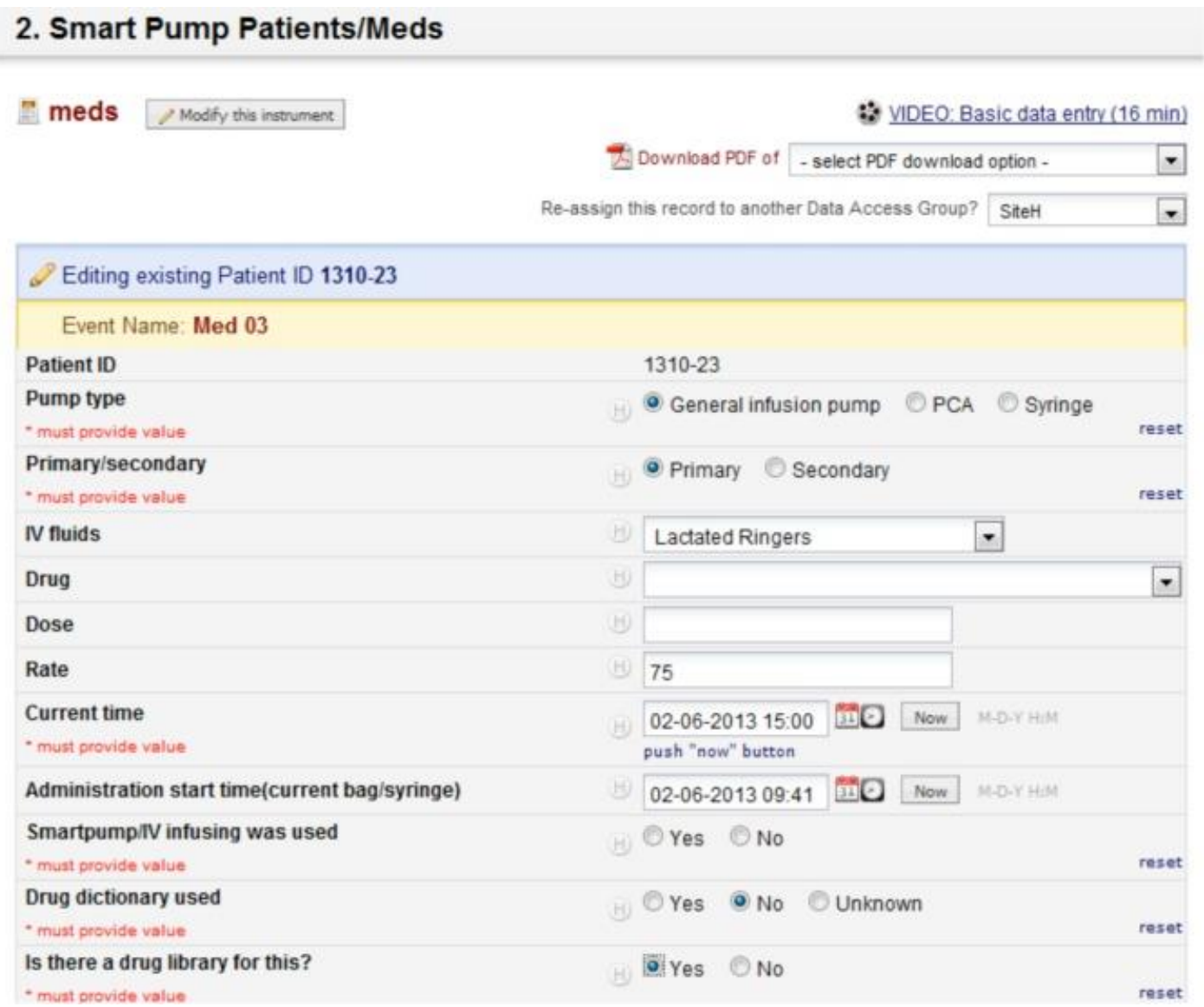

Figure 2. Screen shot of the data collection tool (REDCap). Copied from "Evaluation of Intravenous Medication Errors with Smart Infusion Pumps in an Academic Medical Center," by Ohashi et al., 2013, AMIA Annual Symposium Proceedings, 2013, 10891098. Copyright 2013 by AMIA. Copied with permission. 


\section{EFFICACY OF SMART INFUSION PUMPS}

By using a retrospective medical record review, the second study examined preventable IV-related adverse drug events (ADEs) in ICUs before and after both hospitals replaced conventional pumps with smart pumps (Nuckols, 2008). Both quantitative and qualitative methods were used. The third journal article conducted research as a retrospective pre-post study.

\section{Findings.}

According to the first study conducted by Ohashi et al. (2013), 181 medications were observed during the data period. Of these observations, a whopping $171(94.5 \%)$ had one or more errors associated with their administration, with the largest percentage representing a violation of hospital policy regarding labeling of medications and IV tubing. Regarding actual smart pump handling errors, however, observers found only four incidences. The first two cases involved two clamped medication IV bags, which were supposed to be unclamped/open; the latter two pump errors consisted of one with an incorrect rate and the other with an incorrect medication altogether (Ohashi et al., 2013). Based on these findings, the likelihood of error preventability with smart pump technologies was assessed. Since the first two cases involving the clamped medication bags were intercepted and communicated to the nurses prior to the medication reaching the patient, and since smart pumps at the time of this study couldn't detect secondary IV bag flows, it's impossible to theoretically predict whether an error would have occurred (Ohashi et al., 2013). In error cases 3 and 4, both were human programming errors in which the nurse chose an incorrect IV fluid, in this instance normal saline instead of $1 / 2$ normal saline and programmed an incorrect infusion rate. Fortunately, the mistakes were 


\section{EFFICACY OF SMART INFUSION PUMPS}

non-critical, causing no harm to the patients, but what's concerning is the smart pumps' lack of alerts to the nurse that there may be a problem. Moreover, to achieve maximum patient protection, the article discusses the need for smart pumps to seamlessly integrate or connect with order entry systems and/or the patient's eMAR; the study further comments that only when all medication data including dose, concentration, and rate can be retrieved from physician orders on electronic records in real-time can typing and selecting errors be eliminated (Ohashi et al., 2013). Based on these findings, the four errors were rated unlikely to be prevented by in-use smart pump technology. Table 3 below illustrates these errors and their likelihood to cause harm.

\begin{tabular}{|c|c|c|c|c|c|}
\hline $\begin{array}{l}\text { Error } \\
\text { case } \\
\#\end{array}$ & $\begin{array}{l}\text { NCC } \\
\text { MER } \\
P\end{array}$ & $\begin{array}{l}\text { Type of } \\
\text { error }\end{array}$ & $\begin{array}{l}\text { Medication and } \\
\text { dose infusing via } \\
\text { IV pump }\end{array}$ & $\begin{array}{l}\text { Medical record } \\
\text { order }\end{array}$ & $\begin{array}{l}\text { Likelihood of } \\
\text { preventabilit } \\
\text { y with smart } \\
\text { pump } \\
\text { technology }\end{array}$ \\
\hline 1 & $\mathrm{C}$ & $\begin{array}{l}\text { Clamp } \\
\text { closed }\end{array}$ & $\begin{array}{l}\text { Cefepime } \\
2 \mathrm{~g} / 50 \mathrm{~mL}, \\
16.7 \mathrm{~m} / \mathrm{hr} \\
\text { (observed at } \\
9: 49 \mathrm{am} \text { ) }\end{array}$ & $\begin{array}{l}\text { Cefepime } \\
2 \mathrm{~g} / 50 \mathrm{~mL}, \\
16.7 \mathrm{~m} / \mathrm{hr} \\
\text { administered at } \\
\text { 9:02am }\end{array}$ & No \\
\hline 2 & $\mathrm{C}$ & $\begin{array}{l}\text { Clamp } \\
\text { closed }\end{array}$ & $\begin{array}{l}\text { Phytonadione(vit } \\
\mathrm{K}) 10 \mathrm{mg} / 100 \mathrm{~mL}\end{array}$ & $\begin{array}{l}\text { Phytonadione(vi } \\
\text { t K) } \\
10 \mathrm{mg} / 100 \mathrm{~mL}\end{array}$ & No \\
\hline
\end{tabular}


EFFICACY OF SMART INFUSION PUMPS

\begin{tabular}{|c|c|c|c|c|c|}
\hline $\begin{array}{l}\text { Error } \\
\text { case } \\
\#\end{array}$ & $\begin{array}{l}\text { NCC } \\
\text { MER } \\
P\end{array}$ & $\begin{array}{l}\text { Type of } \\
\text { error }\end{array}$ & $\begin{array}{l}\text { Medication and } \\
\text { dose infusing via } \\
\text { IV pump }\end{array}$ & $\begin{array}{l}\text { Medical record } \\
\text { order }\end{array}$ & $\begin{array}{l}\text { Likelihood of } \\
\text { preventabilit } \\
\text { y with smart } \\
\text { pump } \\
\text { technology }\end{array}$ \\
\hline & & & $\begin{array}{l}50 \mathrm{~mL} / \mathrm{hr} \text { (observe } \\
\text { d at 9:49am }\end{array}$ & $\begin{array}{l}50 \mathrm{~mL} / \mathrm{hr} \\
\text { administered at } \\
9: 02 \mathrm{am}\end{array}$ & \\
\hline 3 & $\mathrm{C}$ & $\begin{array}{l}\text { Right meds } \\
\text { programmed } \\
\text { in correct } \\
\text { channel } \\
\text { /pump }\end{array}$ & $\begin{array}{l}\text { 1/2Normal Saline } \\
125 \mathrm{~mL} / \mathrm{h} \text {, pump } \\
\text { programmed as } \\
\text { Normal Saline }\end{array}$ & $\begin{array}{l}\text { 1/2Normal } \\
\text { Saline } 125 \mathrm{~mL} / \mathrm{h}\end{array}$ & $\begin{array}{l}\text { Yes(with } \\
\text { closed loop } \\
\text { smart pump) }\end{array}$ \\
\hline 4 & $\mathrm{C}$ & $\begin{array}{l}\text { Rate } \\
\text { deviation }\end{array}$ & $\begin{array}{l}\text { Normal Saline } \\
5 \mathrm{~mL} / \mathrm{h}\end{array}$ & $\begin{array}{l}\text { Normal Saline } \\
3 \mathrm{~mL} / \mathrm{h}\end{array}$ & $\begin{array}{l}\text { Yes(with } \\
\text { closed loop } \\
\text { smart pump) }\end{array}$ \\
\hline 5 & $\mathrm{C}$ & $\begin{array}{l}\text { Incorrect } \\
\text { info on label }\end{array}$ & $\begin{array}{l}\text { Heparin } 25,000 \\
\text { unit / } 250 \mathrm{~mL} \text {, } \\
\text { 1250units/hr } \\
12.5 \mathrm{~mL} / \mathrm{hr} \text {, drug } \\
\text { name on a } \\
\text { hospital label } \\
\text { prepared by } \\
\text { nurses was }\end{array}$ & $\begin{array}{l}\text { Heparin 25,000 } \\
\text { unit / } 250 \mathrm{~mL} \text {, } \\
1250 \mathrm{units} / \mathrm{hr} \\
12.5 \mathrm{~mL} / \mathrm{hr}\end{array}$ & No \\
\hline
\end{tabular}




\section{EFFICACY OF SMART INFUSION PUMPS}

\begin{tabular}{|c|c|c|c|c|c|}
\hline $\begin{array}{l}\text { Error } \\
\text { case } \\
\#\end{array}$ & $\begin{array}{l}\text { NCC } \\
\text { MER } \\
P\end{array}$ & $\begin{array}{l}\text { Type of } \\
\text { error }\end{array}$ & $\begin{array}{l}\text { Medication and } \\
\text { dose infusing via } \\
\text { IV pump }\end{array}$ & $\begin{array}{l}\text { Medical record } \\
\text { order }\end{array}$ & $\begin{array}{l}\text { Likelihood of } \\
\text { preventabilit } \\
\text { y with smart } \\
\text { pump } \\
\text { technology }\end{array}$ \\
\hline & & & $\begin{array}{l}\text { wrong(pharmacy } \\
\text { label was correct) }\end{array}$ & & \\
\hline 6 & $\mathrm{C}$ & $\begin{array}{l}\text { Unauthorize } \\
\text { d medication }\end{array}$ & $\begin{array}{l}\text { Normal Saline } \\
5 \mathrm{~mL} / \mathrm{h}\end{array}$ & No order & No \\
\hline
\end{tabular}

Table 3. Examples of errors with potential harms. Copied from "Evaluation of Intravenous Medication Errors with Smart Infusion Pumps in an Academic Medical Center," by Ohashi et al., 2013, AMIA Annual Symposium Proceedings, 2013, 10891098. Copyright 2013 by AMIA. Copied with permission.

According to the second study conducted by Nuckols et al. (2008), of the 100 preventable IV-ADEs that were identified, only 4 cases involved errors matching smartpump features, with two of the cases occurring prior to smart pump implementation and the remaining two cases occurring after smart pump implementation. The majority of preventable IV-ADEs were attributed to other causes. Overall, $29 \%$ of preventable IVADEs involved overdoses, $37 \%$ involved failure to monitor for potential problems, and the remaining $45 \%$ occurred due to the caregiver's failure to intervene when problems appeared (Nuckols et al., 2008). Thus, this study also concluded that smart pumps were relatively unlikely to prevent medication errors since they were responsible for only $4 \%$ of the total number of recorded adverse events. 


\section{EFFICACY OF SMART INFUSION PUMPS}

The hospital in the third study conducted by Guérin et al. (2015) implemented a total of 1,045 smart pumps. The reported number of adverse IV drug events was collected before and after the implementation of smart IV pumps. According to Guérin et al. (2015), a total of 2,911 events were self-reported by clinical staff in the pre-phase $\left(\mathrm{Y}_{0}\right), 3,523$ in the initial post-phase $\left(\mathrm{Y}_{1}\right)$, and 2,788 in the secondary postphase $\left(\mathrm{Y}_{2}\right)$. Since the fluctuations essentially negated one another, this study also concluded that there were no risk reductions associated with the implementation of smart pumps in the 500-bed mother/child hospital.

\section{Limitations.}

All three studies included in this literature review contained limitations. The first study was limited in that it was a point prevalence study, versus a long-term observational study. Ohashi et al. (2013) asserts that collected data on a single day is not always reflective of practices on other days. The sample size was also fairly small at $\mathrm{N}=55$. Regarding limitations with the second study, the authors conclude that they

may have underestimated events matching smart pump functions due to an inability to evaluate smart pump logs or observe its users (Nuckols et al., 2008). This study was also limited in that it didn't include a non-ICU patient population. Lastly, the third study was limited due to its potential for inaccuracies from a lack of reporting all incidents. This is especially true since the events were self-reported and the participants may have feared repercussions for their mistakes. Additionally, this study was limited due to its focus on a specific patient population. 


\section{EFFICACY OF SMART INFUSION PUMPS}

\section{Conclusion.}

This literature review concludes that smart pumps, despite some positive societal hype, have the potential to still cause infusion-related errors. When a barcode medication administration system, CPOE, and the eMAR are all integrated with a smart IV pump, however, this likelihood seems to lessen. Some smart infusion pump vendors, such as Hospira, have accomplished this with the innovation of the Plum $360^{\text {TM }}$ Infusion System. Using Hospira's IV Clinical Integration solution, this pump has the remarkable capability of integrating with the electronic medical record (EMR). By doing so, programming takes place automatically, populating the Plum $360^{\mathrm{TM}}$ Infusion System with medication orders sent directly from the pharmacy or the CPOE system (Hospira, 2017). Patient safety remains at the forefront of this newly designed smart IV pump due to its wireless integration. With the use of Hospira's Plum 360 ${ }^{\mathrm{TM}}$ Infusion System, the chances of not only programming a pump incorrectly are nearly eliminated, but the chances of administering the wrong medication to the right patient are decreased. This, of course, only holds true if the provider prescribes the correct medication, the pharmacist validates the medication as appropriate for the patient, and the nurse also uses critical thinking and sound judgment to confirm clinical appropriateness.

As previously mentioned, the supplementary processes of prescribing, dispensing, and monitoring all play a pivotal role in ensuring that patients receive proper treatments. Ultimately, this literature review revealed that smart infusion pumps might not significantly reduce adverse drug events after all. It is believed, however, that with the expansion of smart pumps' capabilities and functionalities to integrate with the eMAR, a 


\section{EFFICACY OF SMART INFUSION PUMPS}

means of creating a closed loop clinical system, clinical facilities might experience the full benefits of IV smart pumps.

\section{Chapter 3: Methodology}

\section{Research Design.}

This study will be conducted using a descriptive, cross-sectional research design method in which data will be collected and analyzed at a specific point in time.

\section{Population and Sample Design.}

Research will be conducted on the entire obstetrical registered nursing staff at the following five Covenant Health-owned facilities in East Tennessee: Methodist Medical Center in Oak Ridge, TN; Parkwest Medical Center in Knoxville, TN; Fort Sanders Regional Medical Center in Knoxville, TN; LeConte Medical Center in Sevierville, TN; and Morristown-Hamblen Healthcare System in Morristown, TN.

\section{Data Collection Procedure/Instrument.}

Data will be collected via survey research. Informed consent of the nursing staff will be obtained followed by a brief, standardized questionnaire with seven closed-ended questions. The survey, which will be disseminated via the organizations' email system, will be constructed and completed using the free online survey tool, SurveyMonkey®. Recipients will be allotted a week's time to complete the survey. A reminder email will be sent out nearing the week end of the survey deadline. 


\section{EFFICACY OF SMART INFUSION PUMPS}

\section{Response Rate.}

To increase the response rate, and as previously mentioned above, a follow-up with the respondents in the form of a reminder email will be distributed. A response rate of greater than 50 percent is desired.

\section{Profile of Sample.}

Only registered nurses who are practicing one-on-one patient care at the bedside in an inpatient hospital setting will be included in this study. Licensed practical nurses (LPNs) will be excluded. Nurses in administrative and/or non-clinical positions will also be excluded from this study.

\section{Research Questions.}

The collected data from the surveys will be analyzed using descriptive statistics. Specifically, the mean, a measure of central tendency, will be used to provide an arithmetic average of all responses. Most of the obtained data will be compared and displayed on a bar graph. Data results from the second statement which addresses the participants' primary shift, however, will be analyzed and visually displayed using a pie chart.

\section{Chapter 4: Results}

\section{Response Rate of Sample.}

As originally intended, the survey was distributed to a total of 187 registered nurses across the five previously mentioned Covenant Health-owned facilities in East Tennessee. The breakdown for this, according to facility, is as follows: 33 registered 


\section{EFFICACY OF SMART INFUSION PUMPS}

nurses from Methodist Medical Center in Oak Ridge, TN; 45 registered nurses from Parkwest Medical Center in Knoxville, TN; 12 registered nurses from LeConte Medical Center in Sevierville, TN; 72 registered nurses from Fort Sanders Regional Medical Center in Knoxville, TN; and 25 registered nurses from Morristown-Hamblen Healthcare System in Morristown, TN. Of the 187 total nurses who received the survey, 72 nurses completed the survey in its entirety, resulting in a $38.5 \%$ response rate.

\section{Profile of Sample.}

Nurses who had practiced bedside nursing for 4-10 years had the highest survey response rate at $31.94 \%$. Conversely, only $2.78 \%$ of registered nurses having practiced bedside nursing for less than one year completed the survey. Respondents who had practiced bedside nursing for 11-20 years had the same response rate of $22.22 \%$ as respondents with > 20 years of nursing experience. Over half of the survey's respondents work dayshift hours. Nightshift nurses, however, weren't far behind with a response rate of $40.28 \%$. Nurses working PRN or varied shifts had the lowest response rate at $2.78 \%$ and $1.39 \%$, respectively. Nearly $35 \%$ of the survey responses were from nurses $22-30$ years of age. Nurses $>60$ years of age had the lowest response rate at $6.94 \%$. 


\section{EFFICACY OF SMART INFUSION PUMPS}

\section{Research Questions.}

\section{Q1}

How long have you practiced BEDSIDE nursing?

Answered: 72 Skipped: 0

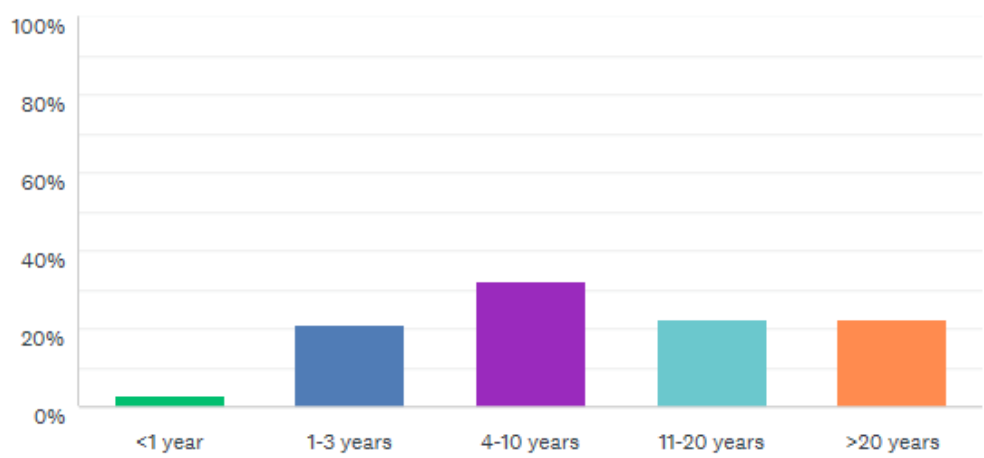

ANSWER CHOICES

- RESPONSES

- <1 year

$2.78 \%$

$20.83 \%$

$31.94 \%$

4-10 years

$22.22 \%$

$22.22 \%$ 


\section{EFFICACY OF SMART INFUSION PUMPS}

\section{Q2}

What shift do you primarily work?

Answered: 72 Skipped: 0

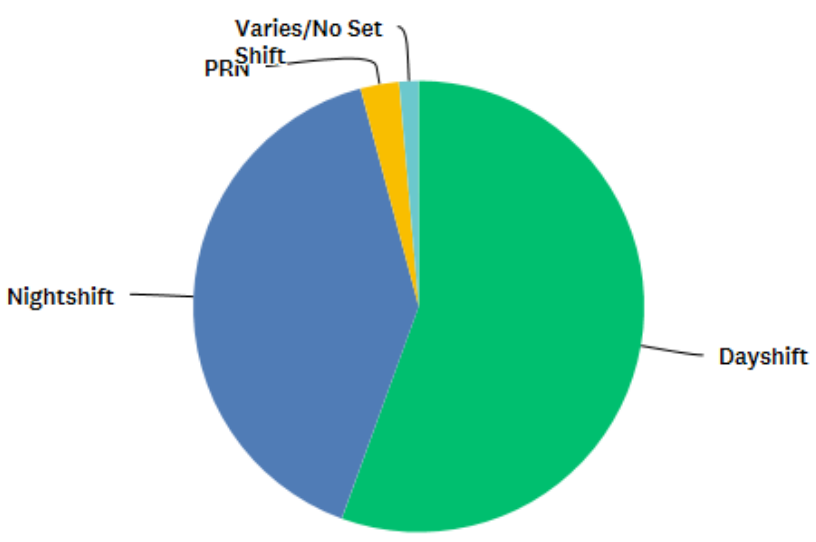

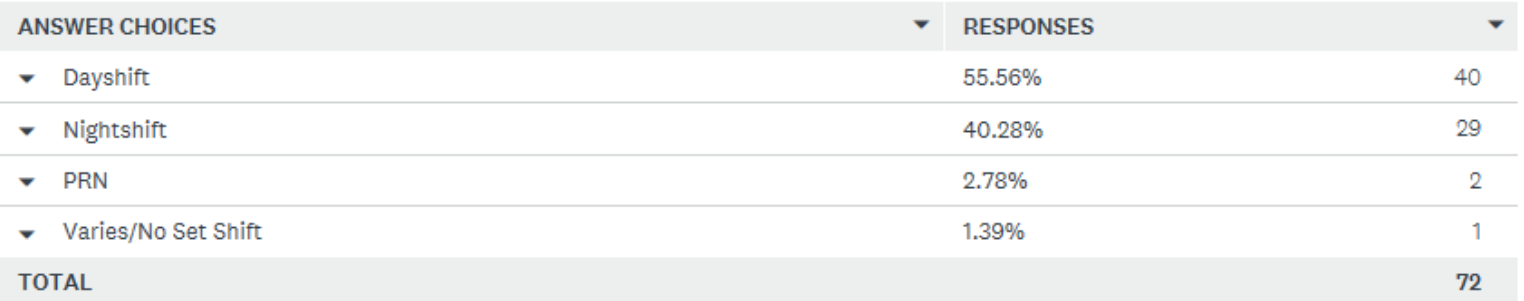




\section{EFFICACY OF SMART INFUSION PUMPS}

\section{Q3}

What is your age?

Answered: 72 Skipped: 0

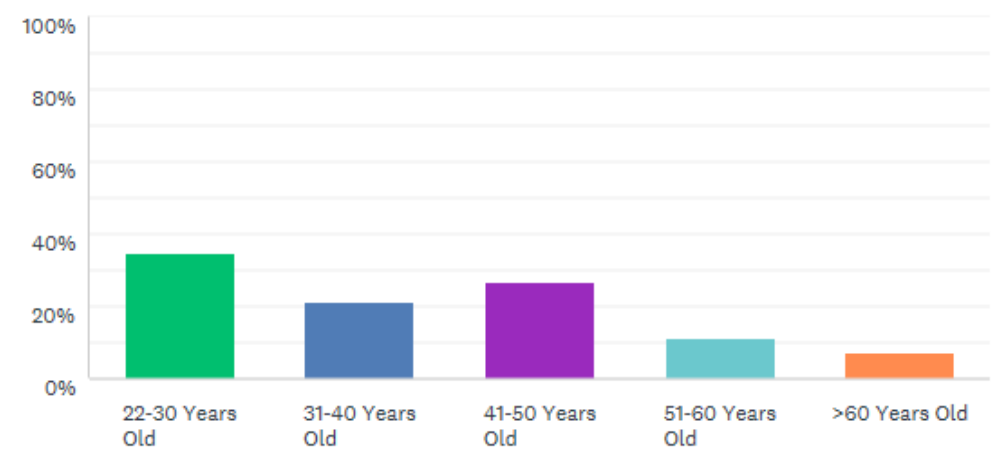

ANSWER CHOICES

- 22-30 Years Old

- 31-40 Years Old

- 41-50 Years Old

51-60 Years Old

- >60 Years Old

TOTAL
- RESPONSES

$34.72 \%$

$20.83 \%$

$26.39 \%$

$11.11 \%$

$6.94 \%$ 


\section{EFFICACY OF SMART INFUSION PUMPS}

\section{Q4}

Smart IV pumps improve patient safety by reducing harm associated with medication errors.

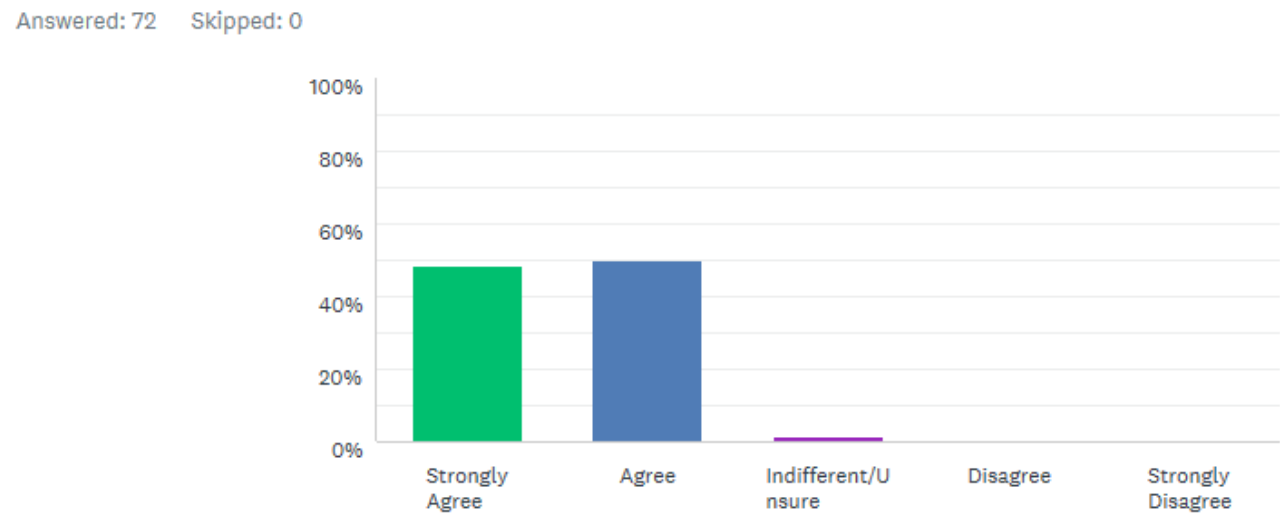

\begin{tabular}{lll} 
ANSWER CHOICES & RESPONSES \\
\hline Strongly Agree & $38.61 \%$ & 35 \\
\hline Indifferent/Unsure & $50.00 \%$ & 36 \\
\hline Disagree & $1.39 \%$ \\
\hline Strongly Disagree & $0.00 \%$ \\
\hline TOTAL & $0.00 \%$ & 0 \\
\hline
\end{tabular}




\section{EFFICACY OF SMART INFUSION PUMPS}

\section{Q5}

The presence of embedded alerts, alarms, and/or functionalities that deny overriding have prevented the following IV-related error(s) in my clinical past (select all that apply):

Answered: 72 Skipped:0

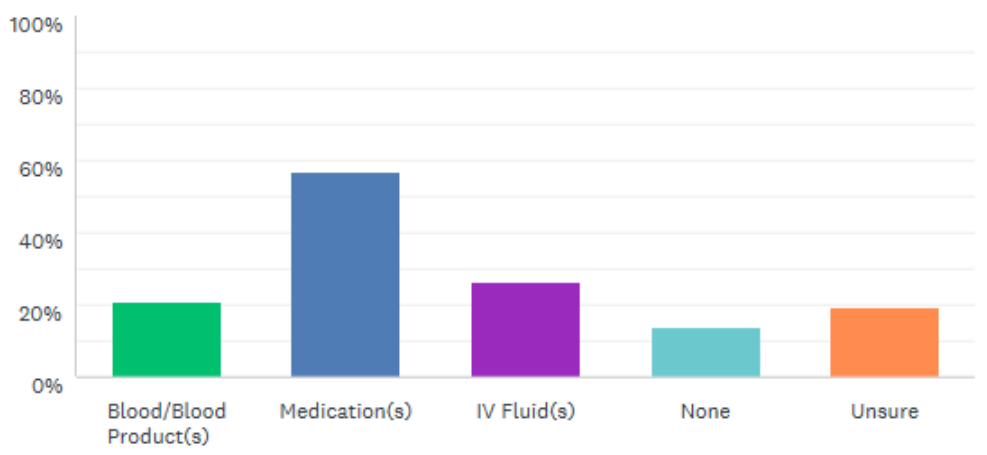

\section{ANSWER CHOICES}

- Blood/Blood Product(s)

Medication(s)

- IV Fluid(s)

- None

- Unsure

Total Respondents: 72
- RESPONSES

$20.83 \% \quad 15$

$56.94 \%$

$26.39 \%$

$13.89 \%$

$19.44 \%$ 


\section{EFFICACY OF SMART INFUSION PUMPS}

\section{Q6}

Learning to operate smart IV pumps is easy and user-friendly. Answered: 72 Skipped: 0

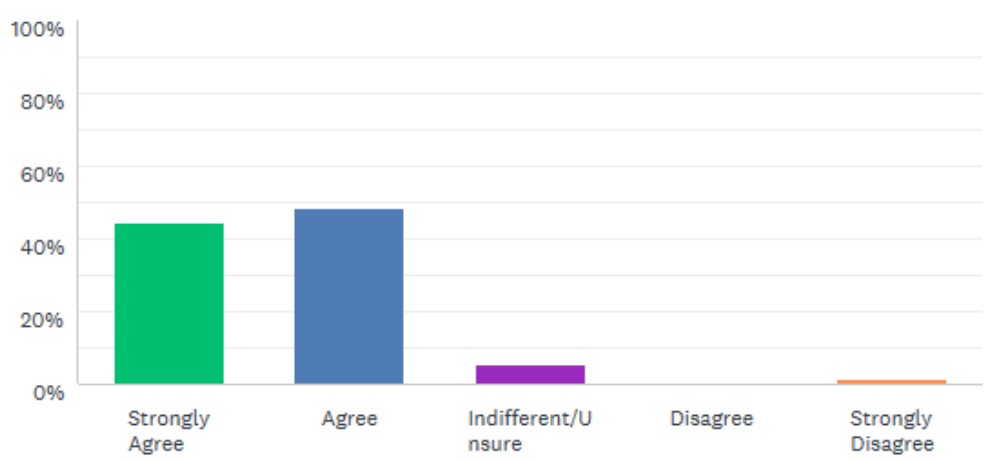

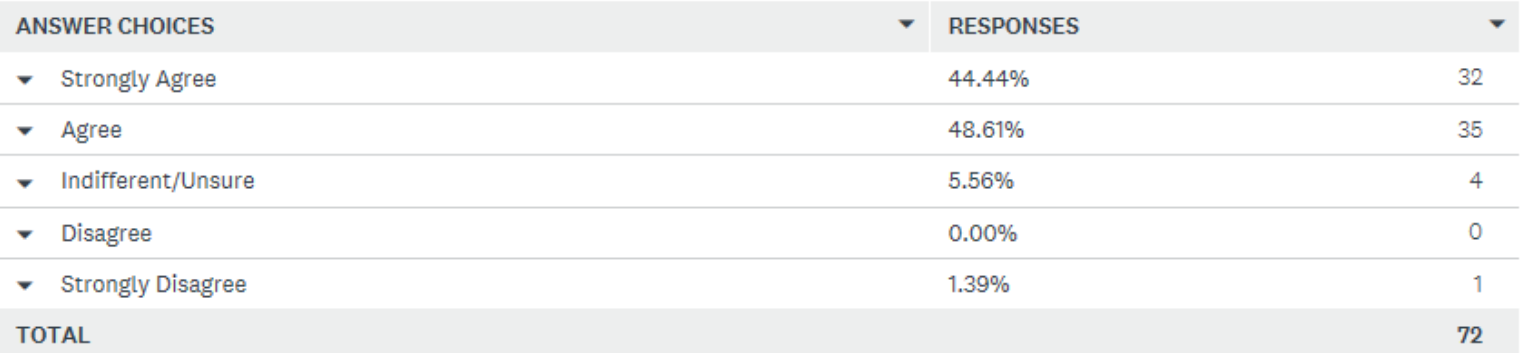




\section{EFFICACY OF SMART INFUSION PUMPS}

\section{Q7}

Smart IV pumps' eventual integration with the eMAR, CPOE, and barcode scanning systems will further improve patient safety (i.e. scanning the patient's armband + scanning the IV infusion(s) = automatic pump programming).

Answered: 72 Skipped:0

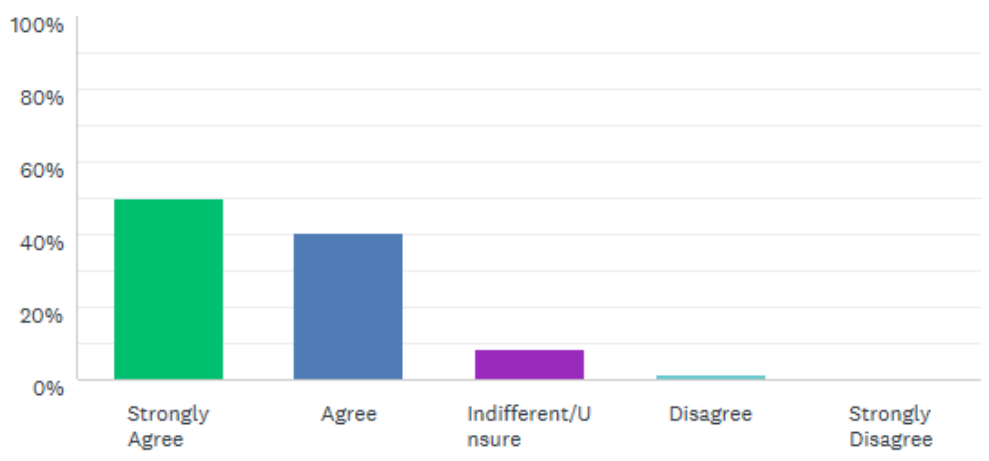

\begin{tabular}{|c|c|c|}
\hline ANSWER CHOICES & RESPONSES & $\checkmark$ \\
\hline Strongly Agree & $50.00 \%$ & 36 \\
\hline - Agree & $40.28 \%$ & 29 \\
\hline - Indifferent/Unsure & $8.33 \%$ & 6 \\
\hline - Disagree & $1.39 \%$ & 1 \\
\hline Strongly Disagree & $0.00 \%$ & 0 \\
\hline TOTAL & & 72 \\
\hline
\end{tabular}




\section{EFFICACY OF SMART INFUSION PUMPS}

\section{Q8}

Comments?

Answered: 18 Skipped: 54

Showing 18 responses

NA

5/7/2018 1:46 AM

View respondent's answers

I would love if we could just scan to program the pump

5/6/2018 2:04 AM

View respondent's answers

i want to set my own pump according to directions and my need

5/4/2018 7:31 AM

View respondent's answers

na

5/3/2018 1:51 PM

View respondent's answers

Use of smart technology can improve clinical safety for patients. Alerts, medications \& rate limits can be customized on a unit level - this level of customization provides a safety net for clinical float staff.

$5 / 3 / 2018$ 10:15 AM

View respondent's answers

$5 / 3 / 2018$ 10:15 AM

View respondent's answers

none

5/3/2018 8:37 AM

View respondent's answers

$\mathrm{n} / \mathrm{a}$

$5 / 3 / 2018$ 2:35 AM

View respondent's answers

na

$5 / 2 / 20182: 47 \mathrm{PM}$

View respondent's answers

NA

5/2/2018 8:38 AM

View respondent's answers

None

5/2/2018 1:07 AM

View respondent's answers 


\section{EFFICACY OF SMART INFUSION PUMPS}

\begin{tabular}{|c|c|}
\hline 5/1/2018 7:57 PM & View respondent's answers \\
\hline \multicolumn{2}{|l|}{$n / a$} \\
\hline 5/1/2018 3:47 PM & View respondent's answers \\
\hline \multicolumn{2}{|c|}{ Better tutorials needed for new hires, as brands and functionality differ between organizations } \\
\hline 5/1/2018 9:51 AM & View respondent's answers \\
\hline \multicolumn{2}{|l|}{ NA } \\
\hline 4/29/2018 1:29 AM & View respondent's answers \\
\hline \multicolumn{2}{|l|}{ none } \\
\hline 4/28/2018 9:52 AM & View respondent's answers \\
\hline \multicolumn{2}{|l|}{ na } \\
\hline 4/27/2018 12:26 AM & View respondent's answers \\
\hline \multicolumn{2}{|l|}{. } \\
\hline 4/26/2018 8:33 AM & View respondent's answers \\
\hline \multicolumn{2}{|l|}{ na } \\
\hline 4/25/2018 5:52 PM & View respondent's answers \\
\hline
\end{tabular}

\section{Chapter 5: Summary, Conclusions, and Recommendations}

\section{Summary of Findings.}

This research study found that nearly all registered nurses agreed that smart IV pumps improve patient safety by reducing harm associated with medication errors. Half of the respondents simply agreed, while $48.61 \%$ strongly agreed. Only one respondent determined indifference/uncertainty. Of the 72 registered nurses who were surveyed, $0 \%$ disagreed or strongly disagreed with smart IV pumps' abilities to improve patient safety. 


\section{EFFICACY OF SMART INFUSION PUMPS}

According to the survey, respondents reported multiple instances in which smart IV pumps had prevented errors in their nursing careers. Of these errors, $56.94 \%$ of respondents stated that smart IV pumps prevented medication errors, $26.39 \%$ of respondents reported prevention of IV fluid errors, $20.83 \%$ of respondents reported prevention of blood/blood product(s)-related errors, $19.44 \%$ were unsure if smart IV pumps had prevented any errors, and the remaining $13.89 \%$ reported that smart IV pumps had not prevented any errors.

A large majority of respondents, $93.0 \%$ to be exact, alleged to some degree that smart IV pumps are easy to operate and user-friendly. Only $5.56 \%$ were indifferent or unsure, while only a single respondent disagreed with this statement. When respondents were asked if smart pumps' eventual integration with the eMAR, CPOE, and barcode scanning systems would further improve patient safety, 50.0\% strongly agreed, $40.28 \%$ agreed, $8.33 \%$ were indifferent or unsure, a single respondent disagreed, and no respondents strongly disagreed with this statement.

The last survey question, a free-text comment box, was provided to elicit supplementary information/opinions. Two commenters supported the use of IV smart pump technology stating, "I would love if we could just scan to program the pump" and the other respondent remarked that "the use of smart technology can improve clinical safety for patients. Alerts, medications, and rate limits can be customized on a unit level and this level of customization provides a safety net for clinical float staff." Another commenter took a different stance as he/she "wants to set my own pump according to directions and my need." And lastly, further input was provided from a respondent who 


\section{EFFICACY OF SMART INFUSION PUMPS}

believes that "better tutorials [are] needed for new hires, as brands and functionality differ between organizations."

\section{Conclusions and Recommendations.}

This unique study which sought to evaluate the efficacy of smart IV pumps from a nursing perspective produced survey results that were largely in favor of smart IV pump technology. This study's results are extremely useful in that no research, to date, has assessed the effectiveness/success of smart IV pump technology from the actual user's perspective. Demographically speaking, the results diversely represent registered nurses of different age groups with various experience levels. Having a near equal percentage of dayshift versus nightshift respondents contributes to the reliability and reality of today's nursing workforce. A plethora of nurses reported multiple instances in which smart IV pumps prevented them from making potentially life-threatening errors. In knowing that IV medications, when compared with medications delivered via other routes, can produce more rapid, potentially irreversible side effects, the fact that $56.94 \%$ of respondents were able to prevent said errors with the use of IV smart pumps is substantial.

It is important to note that the nursing staff that completed this survey currently use smart IV pump technology, but not to its full functionality. Smart IV pumps at the five facilities have yet to be integrated with the eMAR, CPOE, and barcode scanning systems. Because of this, a future study might entail distributing the same survey questions after this integration has occurred for result comparison. Additionally, proper attention should be called to the fact that $>90 \%$ of nurses envision this integration as helpful in improving patient safety. Moreover, based on the number of responses 


\section{EFFICACY OF SMART INFUSION PUMPS}

indicating that a medical error was prevented with the use of smart IV pumps, whether it be related to blood/blood products, medications, and/or IV fluids, and in addition to the nursing staff's positivity regarding ease of use and technological advancements, this study concludes that the use of smart IV pump technology is recommended in today's healthcare facilities.

The implementation of smart pump technology by health systems and hospitals generally requires considerable planning, including identification of stakeholders, evaluation of software capabilities, evaluation of hospital-specific practices, decisions regarding standard operating systems and procedures, building of comprehensive drug libraries, and education of staff before the pumps can be deployed (Reston, 2013). In addition, successful implementation cannot occur without motivated multidisciplinary teams that include not only physicians, pharmacists, and nurses, but also members of the information technology and informatics teams. With patient safety as the driving force, smart infusion pumps, when used appropriately, are becoming an essential technology in healthcare all around the globe. 


\section{EFFICACY OF SMART INFUSION PUMPS}

\section{References}

Association for the Advancement of Medical Instrumentation. (2016). Majority of IV Medication Errors Linked to Clinical Practice Not Technology. Retrieved from http://www.aami.org/newsviews/newsdetail.aspx?ItemNumber=3149

Dulak, S. B. (2005). Technology today: Smart IV Pumps. Rn, 68(12), 38-43. Retrieved from http://eds.b.ebscohost.com.ezproxy.uthsc.edu/eds/pdfviewer/pdfviewer?sid=d480 2de6-2a8b-40c4-975b-636c1ea4feea\%40sessionmgr104\&vid=3\&hid=122

Guérin, A., Tourel, J., Delage, E., Duval, S., David, M. J., Lebel, D., \& Bussières, J. F. (2015). Accidents and incidents related to intravenous drug administration: A pre-post study following implementation of smart pumps in a teaching hospital. Drug Safety, 38(8), 729-736. https://doi.org/10.1007/s40264-015-0308-6

Harding, A. (n.d.). Increasing the Use of 'Smart' Pump Drug Libraries by Nurses: A Continuous Quality Improvement Project. American Journal of Nursing, 112(1), 26-35. Retrieved from http://eds.a.ebscohost.com.ezproxy.uthsc.edu/eds/detail/detail? $\mathrm{vid}=1 \& \operatorname{sid}=609 \mathrm{fd} 4$ e6-66d8-4105-b118b44a46bbb0a0\%40sessionmgr4008\&hid=4108\&bdata=JnNpdGU9ZWRzLWxpd mU\%3d\#AN=000299116200012\&db=edswss

Hospira. (2017). Plum 360 Infusion System: Your Direct Connection to Clinical Excellence. Retrieved from https://www.hospira.com/en/products_and_services/infusion_pumps/plum_360 


\section{EFFICACY OF SMART INFUSION PUMPS}

Husch, M., Sullivan C., Rooney, D., Barnard, C., Fotis, M., Clarke, J., \& Noskin, G. (2005). Insights from the sharp end of intravenous medication errors: implications for infusion pump technology. Qual Saf Health Care, 14(2), 80-86. doi:10.1136/qshc.2004.011957

Nuckols, T. K., Bower, A. G., Paddock, S. M., Hilborne, L. H., Wallace, P., Rothschild, J. M., ... Brook, R. H. (2008). Programmable Infusion Pumps in ICUs: An Analysis of Corresponding Adverse Drug Events. Journal of General Internal Medicine, 23(Suppl 1), 41-45. http://doi.org/10.1007/s11606-007-0414-y

Ohashi, K., Dykes, P., McIntosh, K., Buckley, E., Wien, M., \& Bates, D. W. (2013). Evaluation of Intravenous Medication Errors with Smart Infusion Pumps in an Academic Medical Center. AMIA Annual Symposium Proceedings, 2013, 10891098.

Proctor, L. (2014). Patient Safety \& Quality Healthcare. From Smart Pumps to Intelligent Infusion Systems - The Promise of Interoperability. Retrieved from https://www.psqh.com/analysis/from-smart-pumps-to-intelligent-infusionsystems-the-promise-of-interoperability/

Reston, J. (2013). Chapter 6 Smart Pumps and Other Protocols for Infusion Pumps: Brief Review (NEW) In: Making Health Care Safer II: An Updated Critical Analysis of the Evidence for Patient Safety Practices. Rockville, MD: Agency for Healthcare Research and Quality. Retrieved from https://www.ncbi.nlm.nih.gov/books/NBK133363/pdf/Bookshelf_NBK133363.pd $\mathrm{f}$ 


\section{EFFICACY OF SMART INFUSION PUMPS}

U.S. Food \& Drug Administration. (2016). Medication Error Reports. Retrieved from https://www.fda.gov/Drugs/DrugSafety/MedicationErrors/ucm080629.htm 